—Mattauch-Herzog 型質量分析計における——

\title{
乾板の“二重撮り”法を用いた 高分子量イオンの質量精密測定
}

\author{
Precise Mass Measurement of High Molecular Ions by Photo Plate \\ "Double Exposure" Method with the Mattauch-Herzog Type Mass \\ Spectrometer.
}

\author{
内 藤 統 広* . 篠 光 正 $^{*}$ \\ Motohiro Naito and Mitsumasa Shino
}

(1969年 4 月26日受理)

\begin{abstract}
The "double exposure" method, a new technique which has permitted the precise mass measurement of high molecular ions is described. Some of the results are discussed.
\end{abstract}

\section{1. 緒言}

近年高分解能質量分析計において，分子量が 1,000 を越す試料の質量精密測定が要求されるようになり標 準試料（質量精密測定の際基準となる質量既知のス夕 ンダードスペクトルを与える物質) の点で問題が生じ ている。

現在標準試料としては Perfluorokerosene（以下 P. F. K. と略す) と Perfluorotertiarybuthylamine が最も広く用いられているが，そのスタンダードスペ クトルは $m / \mathrm{e} 831$ までが実用上使用できる限界であ る。これ以上のスタンダードスペクトルを得ることが 重要な課題となり, Triazine 系の標準試料の開発が 行なわれているが, そのスペクトル間のイオン強度比 が大きく変化し使い難く，また現在そのスタンダード スペクトルは $m / \mathrm{e} 1185$ 以下であるなど問題か残る。

そこで写真乾板検出の特微を生かした “二重撮り” 法により，常用の P. F. K. を用いて高分子量イオン の質量精密測定を試み，その方法が従来問題とされて きた高分子量イオンの質量精密測定に非常に有効な方 法であることがわかった。

\section{2, “二重撮り” 法}

Mattauch-Herzog 型質量分析計において乾板は, $m / e$ 值の小さなイオンから大きなものまで同時に高分 解能で検出されるようになっており，また乾板に検出 される mass range は調節可能である。この “二重 撮り”法で高分子量イオン $\mathrm{M}^{+}$の質量精密測定を行 なうには次のような手順でスペクトルを撮る。

$\mathrm{a}$, 乾板の高質量部に $\mathrm{M}^{+}$が検出できるよう, 加速 電圧及び磁場電流を調節してセットし，サンプル と P. F. K. のスペクトルを一緒に撮影する。こ のときの加速電圧を $\mathrm{V}_{1} \mathrm{KV}$ とする。

b . 次に乾板の高質量部に P. F. K. のスペクトル が検出されるように（即ち mass rangeを小さく する）加速電圧を增加して手順 “a”で撮ったス ペクトルの上に P. F. K. のスペクトルを“二重 撮り”する。

このときの加速電圧を $\mathrm{V}_{2} \mathrm{KV}$ とする。

加速電圧 $V_{1} K V$ で手順 “a”により撮つたスペク トルを点線で, 加速電圧 $\mathrm{V}_{2} \mathrm{KV}$ で手順 “ $b$ ”により 撮ったスペクトルを実線で Fig. 1.に示す。

P. F. K. のスペクトルはせいぜい $m / e 831$ 迄しか 検出できないので， $\mathrm{V}_{1} \mathrm{KV}$ で撮つたスペクトルにお いて P.F.K. のスペクトルは高質量部には検出され ていない。

*日本電子株式会社 (東京都昭島市中神町)

Japan Electron Optics Laboratory Co., Ltd. (Nakagami-cho, Akishima-shi, Tokyo). 


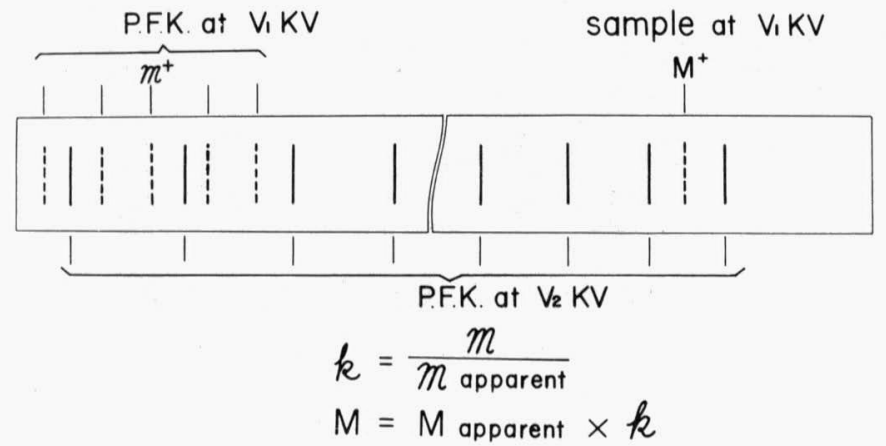

Fig. 1. Double exposure method

$\mathrm{V}_{2} \mathrm{KV}$ で撮った P. F. K. のスペタトルは高質量部 まで娭出されているから，このスペクトルを用いて $\mathrm{M}^{+}$ イオンの質量精密測定を行なうと見かけの質量 $M_{\text {apparent }}$ が求まる。

また $\mathrm{V}_{1} \mathrm{KV}$ で撮ったP. F. K. のスペクトルの 1 本 (質量即知でありその実際の質量を $m$ とする) を $V_{2} \mathrm{KV}$ で撮った P. F. K. で質量精密測定を行なうと見かけ の質量 $m_{\text {apparent }}$ が求まるので, この見かけの質量と実 際の質量との比 $k$ が次のように決まる。

$$
k=\frac{m}{m_{\text {apparent }}}
$$

この比 $k$ は乾板の全領域で一定であるから, 前に求め た $\mathrm{M}^{+}$の見かけの質量 $\mathrm{M}_{\text {apparent }}$ に $k$ を乗ずれば実際 の質量 M が求まる。

$$
\mathrm{M}=\mathrm{M}_{\text {apparent }} \times k
$$

尚この比例定数 $k$ は加速電圧の比 $\mathrm{V}_{2} / \mathrm{V}_{1}$ に一致する。

$$
k=\frac{\mathrm{V}_{2}}{\mathrm{~V}_{1}}
$$

ピークマッチング法による質量精密測定においては, この比 $k$ を抵抗值の変化として読み取るので $\mathrm{V}_{1}$ と $\mathrm{V}_{2}$ との差が大きい $(k>1.1)$ と $k$ の值を正確に求める ことは難しくなる。従ってこの“二重撮り”法では $k$ を求めるとき $V_{2} / V_{1}$ として求めずに乾板上に検出さ れたスペクトルから $m / m_{\text {apparent }}$ として求める。

\section{3. 測 定 例}

\section{1 使用装置}

日本電子製，JMS01SG 二重集束質量分析装置。

\subsection{Tris-Perfluoroheptyl Triazine (M.W.} 1185 ) を被検物質としての測定

この試料の構造式及び電気検出によるスペクトルを Fig. 2. に示す。

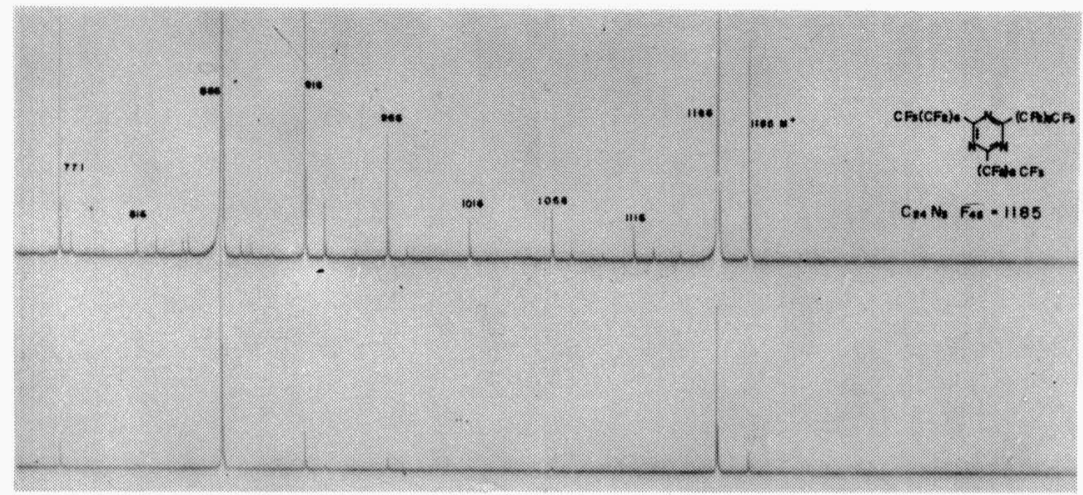

Fig. 2. Tris-perfluorohepthyl triazine 
$m / e 1185$ が乾板上に検出できるように加速電圧 $V_{1}$ を $5 \mathrm{KV}$ とし，加速電圧 $\mathrm{V}_{2}$ は $8 \mathrm{KV}$ とする。“二重 撮り”した段のスペクトル中， $\mathrm{V}_{1} \mathrm{KV}$ の P.F.K. と $\mathrm{V}_{2} \mathrm{KV}$ の P. F. K. の区別がつくように $\mathrm{V}_{1} \mathrm{KV}$ 及び $\mathrm{V}_{2} \mathrm{KV}$ でそれぞれ P. F. K. のみのスペクトルを 1 段 ずつ撮影した。

この模式図と親イオンスペクトル附近の拡大写真を Fig. 3. に示す。尚検出乾板は Ilford- $Q_{2}$ 乾板を用い た。

P. F. K. の $m / e 693 \mathrm{C}_{15} \mathrm{~F}_{27}$ の見かけの質量を測定 し，実際の質量との比をとり $k$ を求める。

$$
k=\frac{m}{m_{\text {apparent }}}=\frac{692.956800}{432.4521}=1.602390
$$

トリアジンのスペクトルの $m / e$ 1185, 1166, 1016, 966，916，の見かけの質量を測定し，これに上記 $k$ を 乗じた結果及び䛊差を Table 1.に示す。

\section{3 Perfluoroalkyl phospholonitrilates} (M. W. 3628) の m/e 3628 の測定

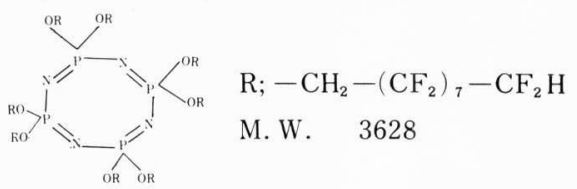

$\mathrm{V}_{1}=1.7 \mathrm{KV}, \mathrm{V}_{2}=8 \mathrm{KV}$ で撮った結果の模式図及び $m / e$ 3628附近の拡大写真 Fig. 4 . に示す。尚検出 乾板は $\mathrm{T} / \mathrm{O}$ 乾板を使用した。

この例では $k$ の值をより正確にするため, P. F. K. の $m / e 605,593,567,555$, につき $k$ を求め, その 平均值 $\bar{k}$ を使用して $m / e 3628$ の実際の質量 $\mathrm{M}$ を求め た。

\section{4. 結び}

この方法により $m / e$ 3628程度までのイオンの質量

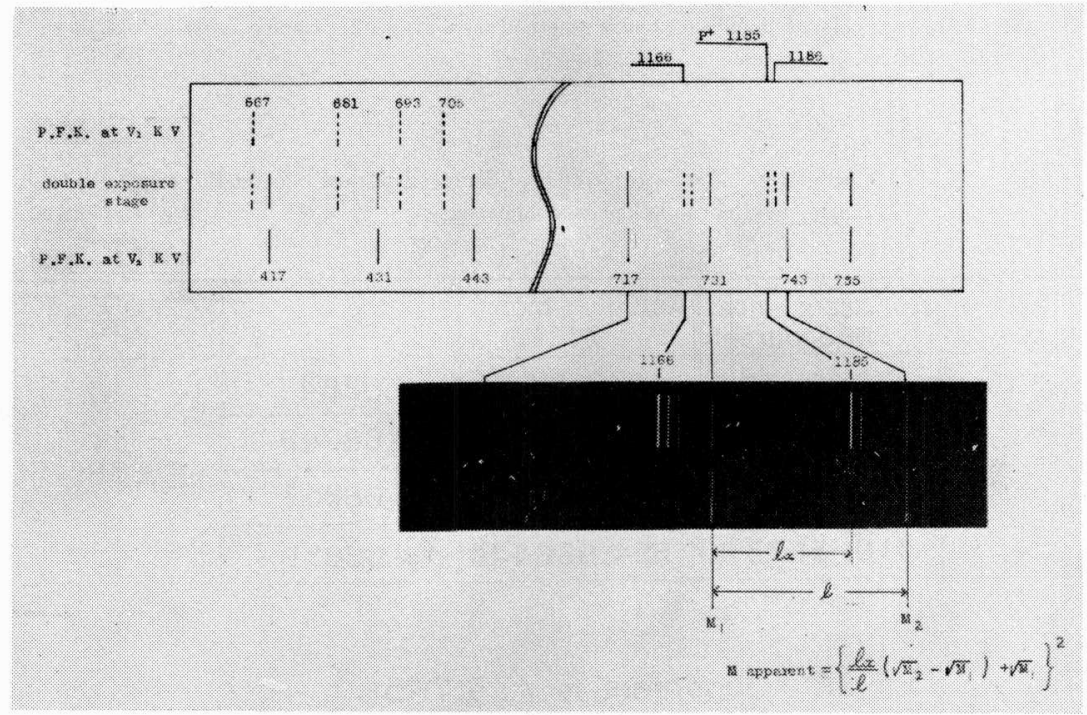

Fig. 3. An example of double exposure method meausrement. Sample; tris-perfluorohepthyl triazine

Table 1. Actual masses and errors of several spectral lines of tris-perfluorohepthyl triazine.

\begin{tabular}{|c|c|c|c|c|}
\hline$m / e$ & $\begin{array}{c}\text { Apparent mass } \\
m_{\text {apparent }}\end{array}$ & $\begin{array}{c}\text { Actual mass } \\
\mathrm{M}_{\text {apparrent }}\end{array}$ & Composition & $\begin{array}{c}\text { error } \\
\text { P.P. M. }\end{array}$ \\
\hline 1185 & 739.4901 & 1184.952 & $\mathrm{C}_{24} \mathrm{~N}_{3} \mathrm{~F}_{45} \quad 1184.937$ & 13 \\
\hline 1166 & 727.6315 & 1165.949 & $\mathrm{C}_{24} \mathrm{~N}_{3} \mathrm{~F}_{44} \quad 1165.939$ & 9 \\
\hline 1016 & 634.0232 & 1015.953 & $\mathrm{C}_{21} \mathrm{~N}_{3} \mathrm{~F}_{38} \quad 1015.949$ & 4 \\
\hline 966 & 602.8229 & 965.957 & $\mathrm{C}_{20} \mathrm{~N}_{3} \mathrm{~F}_{36} \quad 965.952$ & 5 \\
\hline 916 & 571.6207 & 915.959 & $\mathrm{C}_{19} \mathrm{~N}_{3} \mathrm{~F}_{34} \quad 915.955$ & 44 \\
\hline
\end{tabular}


精密測定が10数p. p. m. の誤差で行なわれている。

従って, 従来標準試料の点で困難とされてきた高分
子量イオンの質量精密測定において，常用の P.F.K. を用いた乾板の“二重撮り”法は有効な手段と考える。

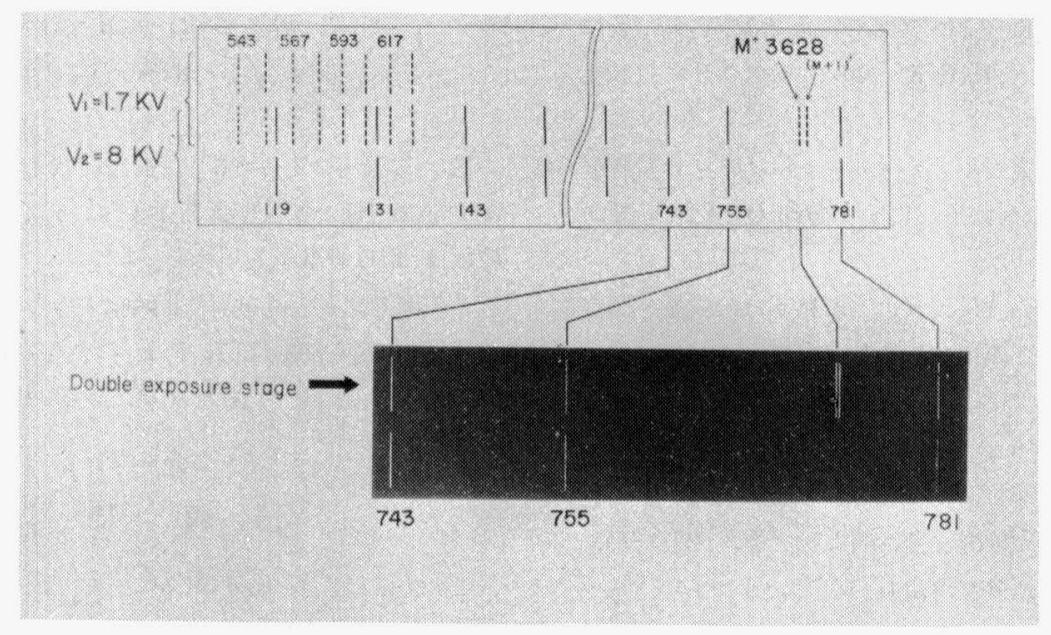

Fig. 4. An example of double exposure method measurement. Sample; perfluoroalkyl phospholonitrilates

Table 2. A measurement of $m / e 3628$ by "double exposure" method. Sample; Sample; perfluoroalkyl phospholonitrilates

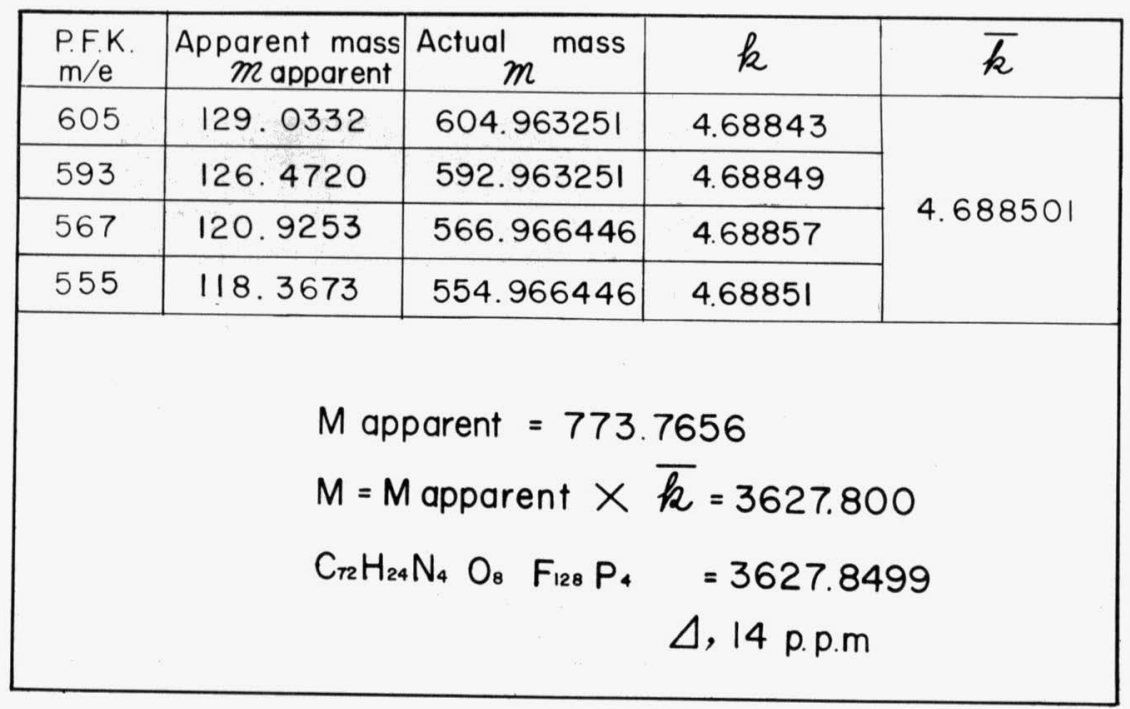

